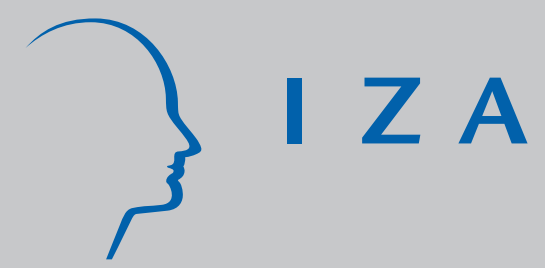

IZA DP No. 9143

Increasing Coverage of Antiretroviral Therapy and Male Medical Circumcision in HIV Hyperendemic Countries: A Cost-Benefit Analysis

Pascal Geldsetzer

David E. Bloom

Salal Humair

Till Bärnighausen

June 2015 


\section{Increasing Coverage of Antiretroviral Therapy and Male Medical Circumcision in HIV Hyperendemic Countries: A Cost-Benefit Analysis}

\author{
Pascal Geldsetzer \\ Harvard T.H. Chan School of Public Health
}

\section{David E. Bloom}

Harvard T.H. Chan School of Public Health and IZA

\author{
Salal Humair \\ Harvard T.H. Chan School of Public Health
}

Till Bärnighausen

Harvard T.H. Chan School of Public Health and University of KwaZulu-Natal

Discussion Paper No. 9143

June 2015

IZA

P.O. Box 7240

53072 Bonn

Germany

Phone: $+49-228-3894-0$

Fax: +49-228-3894-180

E-mail: iza@iza.org

Any opinions expressed here are those of the author(s) and not those of IZA. Research published in this series may include views on policy, but the institute itself takes no institutional policy positions. The IZA research network is committed to the IZA Guiding Principles of Research Integrity.

The Institute for the Study of Labor (IZA) in Bonn is a local and virtual international research center and a place of communication between science, politics and business. IZA is an independent nonprofit organization supported by Deutsche Post Foundation. The center is associated with the University of Bonn and offers a stimulating research environment through its international network, workshops and conferences, data service, project support, research visits and doctoral program. IZA engages in (i) original and internationally competitive research in all fields of labor economics, (ii) development of policy concepts, and (iii) dissemination of research results and concepts to the interested public.

IZA Discussion Papers often represent preliminary work and are circulated to encourage discussion. Citation of such a paper should account for its provisional character. A revised version may be available directly from the author. 


\section{ABSTRACT \\ Increasing Coverage of Antiretroviral Therapy and Male Medical Circumcision in HIV Hyperendemic Countries: A Cost-Benefit Analysis}

HIV continues to cause the largest number of disability-adjusted life years of any disease in HIV hyperendemic countries (i.e., countries with an adult HIV prevalence $>15 \%$ ). We compare the benefits and costs of two proven biological interventions to reduce the health losses due to the HIV epidemic in hyperendemic countries from 2015 through 2030: 1) increasing ART coverage to $90 \%$ among HIV-infected adults with a CD4-cell count $<350$ cells/microliter, before expanding the HIV treatment scale-up to people with higher CD4-cell counts; and 2) increasing male medical circumcision coverage to at least $90 \%$ among HIVuninfected adult men. We developed a mathematical model to determine the benefits and costs of increasing the coverage of both ART under different CD4-cell count thresholds and of circumcision in HIV-hyperendemic countries. The results show that scaling up ART and circumcision are both cost-beneficial. However, the benefit-to-cost ratio (BCR) for circumcision is significantly higher than for ART: 7.4 vs. 3.0 (at US $\$ 1,000$ per life year and a $5 \%$ discount rate) and 56.4 vs. 16.3 (at US\$5,000 per life year and a 3\% discount rate). The additional cost of scaling up circumcision is approximately $\$$ US500 million while the additional cost of increasing ART coverage lies between \$US17 and \$US19 billion. We conclude that increasing the coverage of ART among HIV-infected adults with a CD4-cell count $<350$ cells/microliter and, in particular, scaling up male medical circumcision among HIV-negative men are both highly cost-beneficial interventions to reduce the health burdens resulting from the HIV epidemic in hyperendemic countries over the next 15 years.

JEL Classification: D61, I18

Keywords: HIV, male medical circumcision, antiretroviral therapy, cost-benefit analysis

Corresponding author:

Pascal Geldsetzer

Department of Global Health \& Population

Harvard T.H. Chan School of Public Health

677 Huntington Avenue

Boston, MA 02115

USA

E-mail: pag395@mail.harvard.edu 
Thirty years after the human immunodeficiency virus (HIV) was first identified, the HIV epidemic continues to cause large-scale human suffering and economic losses. In 2012, an estimated 35.5 million people were living with HIV and 1.6 million people died of HIV/AIDS (UNAIDS, 2013b); and, as of 2012, 17.8 million children lost one or both parents due to HIV (UNICEF, 2014). Economically, HIV is projected to continue to slow economic growth in sub-Saharan Africa, the region with the highest HIV burden, for many years to come (UNAIDS, 2005; Vasilakis, 2012).

\section{An unprecedented global commitment}

HIV/AIDS features prominently in the Millennium Development Goals (MDGs) with MDG 6a focusing on reducing incidence ("to have halted by 2015 and begun to reverse the spread of HIV/AIDS") and MDG 6b on treatment ("to achieve, by 2010, universal access to treatment for HIV/AIDS for all those who need it”) (United Nations, 2014). Since the formulation of these goals, HIV has not only received the largest amount of donor funding of all health-related MDGs (Dieleman et al., 2014), but the international HIV response evolved into an unprecedented global political and financial commitment to a single disease. Politically, HIV has been the focus of three UN General Assembly Declarations; the first recognizing the HIV/AIDS epidemic as a "global emergency" (United Nations, 2001); the second one resolving to achieve "universal access to comprehensive prevention programs, treatment, care and support” by 2010 (United Nations, 2006); and the third pledging to intensify efforts to eliminate HIV and AIDS (United Nations, 2011). Financially, resources available for HIV programs in low- and middle-income countries increased from an estimated value of US\$2.1 billion ${ }^{1}$ in 2001 to US\$19.5 billion in 2012 of which US\$9.2

\footnotetext{
${ }^{1}$ All dollar amounts in this paper are shown as US dollar values for 2014.
} 
billion were from international sources (UNAIDS, 2013b). In fact, HIV alone received 25\% of international development assistance for health in 2011 (Dieleman et al., 2014).

\section{Looking to the future: HIV as an unfinished agenda}

This impressive commitment to HIV has led to significant successes in halting and reversing the epidemic. The annual number of new HIV infections globally is estimated to have decreased by 33\% (from 3.4 to 2.3 million) between 2001 and 2012 (UNAIDS, 2013b). In addition, 9.7 million people globally received life-saving antiretroviral therapy (ART) in 2012, and the annual number of deaths due to AIDS declined by more than $30 \%$ between 2005 and 2012 (UNAIDS, 2013b).

Yet, MDG6 will not be achieved by 2015, and the HIV epidemic is still one of the most important causes of loss of life and health in sub-Saharan Africa. In fact, HIV still causes the largest number of disability-adjusted life years (DALYs) among all diseases in Eastern and Southern Africa (Ortblad, Lozano, and Murray, 2013). An important reason for this high disease burden is that in 2012, only about six out of 10 people living with HIV in subSaharan Africa and needing ART under current national treatment guidelines (CD4 count ${ }^{2}$ $\leq 350 / \mu 1$ ) received ART (UNAIDS, 2013a). Moreover, immunological and virological failure rates among those receiving ART in the region are commonly high (Aghokeng et al., 2014). Clearly, therefore, national and international development strategies after 2015 cannot ignore the HIV epidemic. Importantly, the successes of the past ART scale-up are vulnerable to discontinuation of investments; only by continuing ART provision to those currently receiving ART can the mortality and morbidity reductions of the past be maintained.

\footnotetext{
${ }^{2}$ The CD4 T-helper cells are immune system cells that are targeted by HIV. The CD4-count, therefore, tends to decrease in HIV-infected individuals as their immune systems increasingly weaken during the course of the disease.
} 
However, international donors have not increased the level of spending on HIV since 2009, which is expected to remain stagnant over the coming years (UNAIDS, 2013b). In the face of obvious resource constraints and a persisting HIV burden, we propose two goals that will generate the highest return on investment in addressing the unfinished HIV agenda.

\section{Two goals to address the HIV epidemic in the most affected countries}

Sub-Saharan Africa is home to 70\% of those living with HIV globally (UNAIDS, 2013b). Within Africa, the Southern region has been hit hardest by the epidemic. In fact, all hyperendemic countries (countries with an adult HIV prevalence greater than 15\%; UNAIDS, 2014b) are located in Southern Africa. These are currently Botswana, Lesotho, South Africa, Swaziland, and Zimbabwe (WHO, 2014b). These two goals address the HIV epidemic in hyperendemic countries for the period 2015 to 2030:

Goal 1: Achieve ART coverage of at least 90\% among HIV-infected adults with a CD4 count $<350$ cells/ $\mu \mathrm{L}$ before expanding the HIV treatment scale-up to people with higher CD4 counts.

Goal 2: Attain circumcision coverage of at least 90\% among HIV-uninfected adult men.

This paper first explains why these two goals are the most cost-beneficial measures for HIV. Then the paper presents the assumptions, structure, and results of a model built to calculate the costs and benefits of scaling up ART and male medical circumcision (MMC). Finally, the paper discusses implementation challenges for both goals. 


\section{Why focus ART first on those most in need?}

Since the advent of antiretroviral drugs, the WHO has gradually increased its recommended threshold for starting patients on ART to include increasingly healthy patients. WHO treatment thresholds are based on the CD4 count, a cell count that decreases in concentration with deteriorating immune system function. In 2006, the WHO issued a recommendation that patients with a CD4 count $<200$ cells/ $\mu \mathrm{L}$ should be started on ART (WHO, 2006). In 2010, this threshold was increased to $<350$ cells/ $\mu \mathrm{L}$ (WHO, 2010a) before it was further increased to $<500$ cells $/ \mu \mathrm{L}$ in 2013 (WHO, 2013). These increases, while not without controversy, were based on evidence that earlier ART benefits patients' health. In 2011, a clinical trial, hailed as a game changer in the HIV field, provided evidence for even earlier initiation of ART. It showed that providing ART early in the course of the disease reduces the chance of an infected person passing HIV to an uninfected partner by 96\% (Cohen et al., 2011). Similarly, at the population level, Tanser et al. found that increasing ART coverage in the general community is associated with a reduced risk of HIV acquisition (Tanser et al., 2013), strengthening evidence that led to calls for using HIV treatment as prevention (TasP). Currently, several large ongoing trials aim to establish the causal effect of providing ART to all HIV patients regardless of CD4 count, i.e. TasP, when implemented at the population level in sub-Saharan Africa (Essex, DeGruttola, Lebelonyane, \& Habibi, 2013; Havlir \& Kamya, 2013; Hayes et al., 2014; Iwuji et al., 2013; Stop AIDS Now!, 2014).

In an utopian scenario of unlimited resources, few would dispute that all HIV-infected individuals should be offered ART regardless of their CD4 count given the current evidence base for providing ART early in the course of the infection. However, in the real world where financial and human resources are limited, countries in sub-Saharan Africa, including the 
hyperendemic countries in Southern Africa, are still far from reaching universal ART coverage among those with lower CD4 counts. As of 2012, only an estimated $61 \%$ of all HIV-infected individuals with a CD4 count $<350$ cells $/ \mu \mathrm{L}$ and $34 \%$ of those with a CD4 count $<500$ cells $/ \mu \mathrm{L}$ were receiving ART in sub-Saharan Africa (UNAIDS, 2013b), in part because only about half (48\%) of those infected with HIV know their status (UNAIDS, 2014a). Compared with providing ART only to those with a CD4 count $<350$ cells $/ \mu \mathrm{L}$, TasP would roughly double the number of ART-eligible patients in hyperendemic countries (UNAIDS, 2013b, 2014a). Given that ART is expensive, TasP would undoubtedly require very large additional financial investments. Using a discount rate of $3 \%$, an estimate indicated that implementing TasP in South Africa, the hyperendemic country with the largest absolute number of HIV-infected individuals, would have costed an additional US\$11.8 billion in 2009 over the following 12 years as compared with maintaining the current coverage level of ART (Bärnighausen, Bloom, and Humair, 2012a). This raises a fundamental question about resource allocation in hyperendemic countries: Should TasP be implemented immediately, or should resources be targeted first at the unfinished agenda of achieving universal coverage among those most in need of treatment before offering ART to those with higher CD4 counts? We recommend the latter approach for two main reasons.

The first reason is that providing ART to an individual with a CD4 count $<350$ cells $/ \mu \mathrm{L}$ is, on average, more cost effective than offering ART to a patient with a higher CD4 count because the weaker a patient's immune system is, the more dramatic is their health status improvement with ART. Additionally, the preventive effect of ART is higher among those with lower CD4 counts because, with the exception of a very early acute infection stage lasting one to four months, patients with CD4 $<200$ cells $/ \mu \mathrm{L}$ are significantly more infectious than those with higher CD4 counts (Hollingsworth, Anderson, and Fraser, 2008). Thus, by 
providing ART to those with lower CD4 counts before gradually offering it to healthier HIVinfected patients, the hyperendemic countries would target the sharpest slope of the gradient of cost effectiveness before they incrementally roll out ART to all those who need it.

The second reason for a gradual rollout of ART from sickest to healthiest patients is that implementing TasP immediately may lead to a "crowding-out" effect whereby healthier patients may prevent sicker ones from receiving ART (Bärnighausen, Bloom, and Humair, 2014; Bärnighausen, Humair, and Bloom, 2012b). Such a crowding-out effect arises when human, financial, or physical resources are insufficient to provide ART to all eligible HIVinfected people in hyperendemic countries. In this case, providing ART to a somewhat healthy patient may imply that a less healthy patient cannot receive the life-saving treatment. Several mechanisms can generate crowding-out effects. Sicker patients are physically weaker and are therefore, on average, less able to travel to the next ART clinic and wait, often for hours, to be seen by a health worker than their healthier peers. Similarly, patients in more advanced stages of HIV disease are less likely to be employed than patients in earlier stages of the disease. They may therefore be less able to afford the out-of-pocket expenditures associated with treatment, such as for transport. Crowding-out effects are not only highly undesirable based on cost-effectiveness reasoning but also based on ethical grounds; they would violate most conceptions of fairness in access to health care. Offering ART to people in earlier stages of HIV disease only when all, or nearly all, people in later disease stages are receiving ART will prevent crowding-out effects.

\section{Why circumcision?}

If effectively implemented, male medical circumcision (MMC) is plausibly a highly costbeneficial intervention to address the HIV epidemic for several reasons. First, MMC has been 
shown to be efficacious in preventing new HIV infections: three phase-III clinical trials conducted in South Africa, Kenya, and Uganda have shown that MMC has an efficacy of around $60 \%$ in reducing HIV acquisition by men through heterosexual intercourse (Auvert et al., 2005; Bailey et al., 2007; Gray et al., 2007). Second, while MMC targets men, after some delay, rates of infection in women also reduce substantially as fewer of their sexual partners are infected. Third, MMC is a one-off intervention that lasts for life (in contrast to, e.g., antiretroviral drugs that have to be administered continuously). Fourth, the implementation costs of MMC will be comparatively low as the procedure does not require expensive equipment or medications and does not necessarily require a physician or surgeon (WHO, 2008). Fifth, great potential exists for scaling up MMC in hyperendemic countries and subSaharan Africa as a whole. In 2007, WHO and UNAIDS selected 13 African countries to scale up MMC to 80\% of HIV-uninfected men between the ages of 15 and 49 years by 2016 . These countries collectively only reached $28 \%$ of this target by the end of 2013, with only Nyanza province in Kenya (85\% of target reached) achieving more than $50 \%$ of the target (WHO, 2014a). Yet, the level of acceptability of MMC is encouraging with a review finding that a median of $65 \%$ of uncircumcised men in sub-Saharan Africa are willing to be circumcised (Westercamp and Bailey, 2007).

\section{A model to project the cost-benefits of ART and circumcision}

We have developed a mathematical model to determine the cost effectiveness of increasing ART coverage under different CD4 count thresholds and of MMC in HIV-hyperendemic countries. A detailed description of the model and its assumptions can be found elsewhere (Bärnighausen et al., 2012a; Eaton et al., 2012). Here, we build on this model to determine the costs and benefits of scaling up ART among HIV-infected individuals with a CD4 count $<350$ cells/ $\mu \mathrm{L}$ (henceforth referred to simply as ART) and MMC among HIV-uninfected 
adult men in all five hyperendemic countries globally. We parameterize the model using data from South Africa, but we scale the model to apply to all hyperendemic countries. While the UNAIDS categorization into hyperendemic countries is somewhat arbitrary, as it is merely based on HIV prevalence, the HIV epidemics in these countries have some common characteristics in addition to a very high prevalence. These epidemic characteristics include that the virus circulates in the general population, that heterosexual sex is the main mode of transmission, and that women are infected earlier in life than men and represent the majority of HIV-infected individuals in these countries (UNAIDS, 2013b, 2014b).

The model analytically computes the number of new HIV infections and the number of HIVrelated deaths for different coverage combinations of ART and MMC using both behavioral and biological variables, such as the HIV transmission probability per sex act, the number of sex acts per time unit, and the number of sex partners. Compared with other models that typically furnish cost-effectiveness estimates of single HIV interventions, this model allows us to project the combined effects of multiple HIV interventions that may affect different biological or behavioral variables, as discussed in Bärnighausen et al. (2012a). Further, the outputs from this model have been found to be in agreement with the outputs of 11 other HIV models (Eaton et al., 2012). Figure 1 provides an overview of the model's basic structure. 


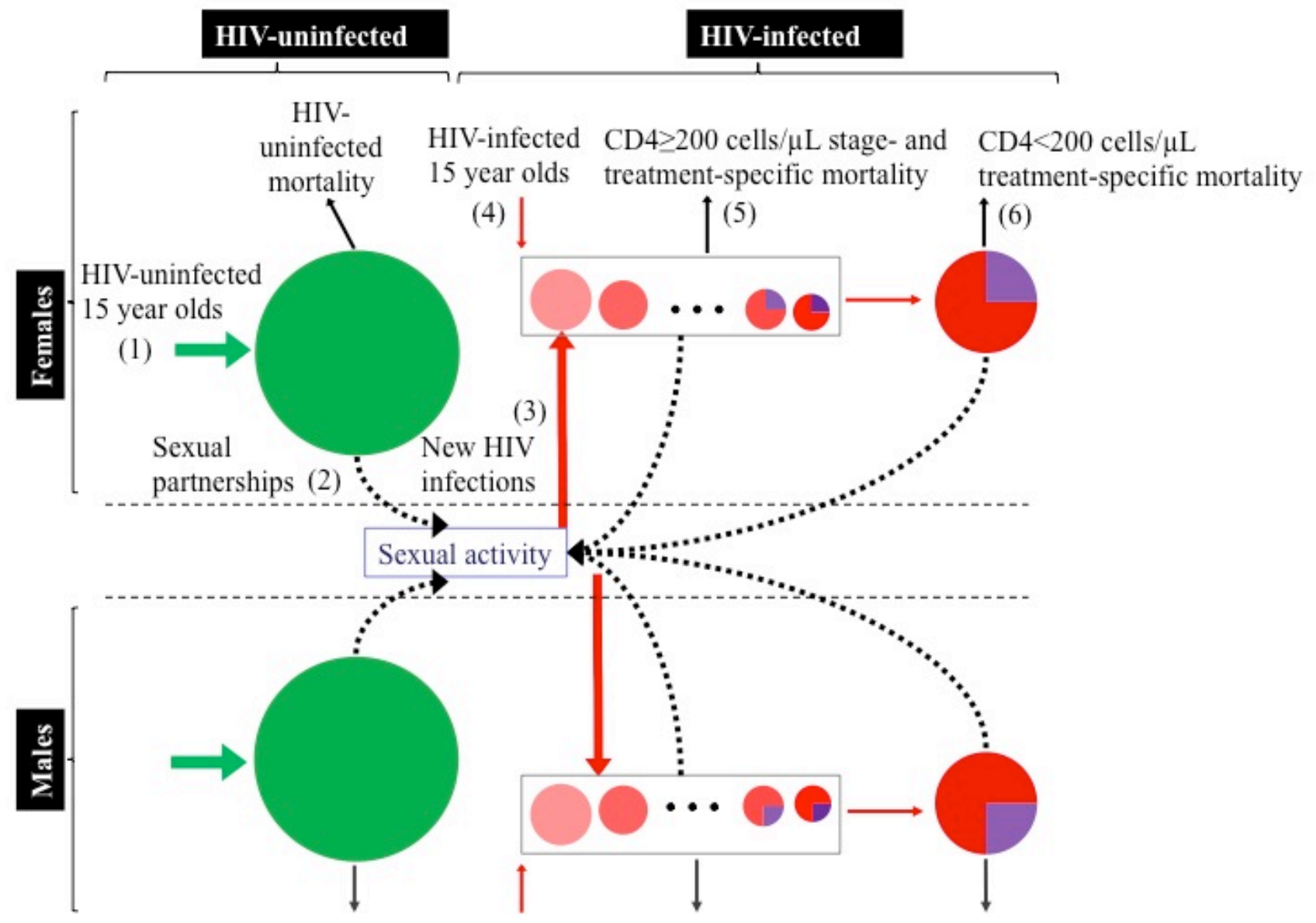

Fig. 1. Diagrammatic summary of the model. (1) HIV-uninfected individuals enter the pool of uninfected sexually active people. (2) Sex acts occur between HIV-uninfected individuals and other HIV-uninfected and HIV-infected individuals. (3) Sex acts between HIV-uninfected and HIV-infected individuals lead to new HIV infections. (4) These newly infected individuals together with HIV-infected 15-year olds add to the pool of HIV-infected individuals. (5) HIV-infected individuals progress through different stages of the disease. (6) When the disease has progressed to the point that the CD4 count drops below 200 cells $/ \mu \mathrm{L}$, the individual dies and drops out of the pool of HIV-infected individuals. The purple color represents those individuals who receive ART.

Source: Adapted from Bärnighausen et al. (2012a).

The following two assumptions need to be kept in mind when interpreting the model's results. First, given that ART is very effective in halting disease progression, the model assumes that an HIV-infected individual will not progress to the next stage of the disease as long as the person is on ART. Second, it assumes that MMC provides protection from HIV over and above that offered by ART because MMC and ART operate through different biological mechanisms. Thus, if a circumcised HIV-uninfected man has sex with an HIVinfected partner who is receiving ART, the per sex act HIV acquisition probability of the 
circumcised man is $40 \%$ of the reduced transmission probability due to the partner being on ART. This assumption is plausible, as discussed in Bärnighausen et al. (2012a).

For each calendar year between 2015 and 2030, the model computes the cost of the interventions and number of HIV-related deaths if ART or MMC had been scaled up. The scenario that serves as a comparison, i.e. the counterfactual, is the cost and number of HIVrelated deaths when maintaining the approximate current coverage levels of ART (50\% among those with a CD4 count $<350$ cells $/ \mu \mathrm{L}$; WHO, 2014b) and MMC (45\% among adult men; Williams et al., 2006). The two scenarios compared with this benchmark scale up MMC among adult men (90\% MMC and 50\% ART coverage) or scale up ART (45\% MMC and 90\% ART coverage). By subtracting the number of deaths in each intervention scenario from the number of deaths in the counterfactual scenario, we calculated the number of deaths averted in each calendar year for each ART and MMC scale-up scenario. We convert deaths averted into life years gained by multiplying the number of deaths averted by an estimate of the number of life years that the person has gained through the aversion of his or her death. We arrived at this estimate by assuming 1) that the age at which the person would have contracted HIV is the mean age of infection, which we calculated from data collected in KwaZulu-Natal in the largest population cohort in Southern Africa (Tanser et al., 2013); 2) that without ART a person would die 10 years after the age of infection, as 10 years is the approximate time from infection until death without ART (Bacchetti and Moss, 1989; Bailey, 1997); and 3) that the individual has a life expectancy of 70 years, which is the HIV causedeleted life expectancy for rural South Africa (Bor et al., 2013). Using this approach, we calculated that, on average, an undiscounted 33.5 years of life are gained for each death averted. 


\section{Findings}

Table 1 shows the projected life years gained and the implementation costs for each of the two goals. Under each discount rate, 3\% and 5\%, the life years gained are more than 10 times higher for ART as compared with MMC. However, compared with maintaining current coverage levels of ART and MMC, the additional cost of scaling up MMC is only about US $\$ 500$ million, while the additional cost of scaling up ART is US\$16.5 to US\$19.3 billion. In fact, as the projected cost of maintaining the current coverage levels of ART and MMC lies between US\$15.8 (5\% discount rate) and US\$17.9 (3\% discount rate) billion, the cost of scaling up ART would require an additional 92-122\% investment while rollout of MMC would only need roughly 3\% in additional investment. The main reason for this discrepancy in implementation costs is that ART is a continuous healthcare service, which entails expensive long-term medications, while MMC is a one-off procedure.

Table 1. Life years gained and cost of each goal

\begin{tabular}{|c|c|c|c|c|c|c|}
\hline \multirow{2}{*}{ Goal } & \multicolumn{3}{|c|}{ 3\% Discount } & \multicolumn{3}{|c|}{$\mathbf{5 \% \text { Discount }}$} \\
\cline { 2 - 6 } & $\begin{array}{c}\text { Life years } \\
\text { gained } \\
\mathbf{( 1 , 0 0 0 s )}\end{array}$ & $\begin{array}{c}\text { Cost } \\
\text { (US\$1,000s) }\end{array}$ & $\begin{array}{c}\text { Additional } \\
\text { cost } \\
\text { (US\$1,000s) }\end{array}$ & $\begin{array}{c}\text { Life years } \\
\text { gained } \\
\mathbf{( 1 , 0 0 0 s )}\end{array}$ & $\begin{array}{c}\text { Cost } \\
\text { (US\$1,000s) }\end{array}$ & $\begin{array}{c}\text { Additional } \\
\text { cost } \\
\text { (US\$1,000s) }\end{array}$ \\
\hline $\begin{array}{c}\text { Goal 1: } \\
\text { 90\% ART } \\
\text { coverage }\end{array}$ & 64,106 & $37,190,000$ & $19,311,250$ & 48,843 & $32,193,300$ & $16,452,647$ \\
\hline $\begin{array}{c}\text { Goal 2: } \\
90 \% \text { MMC } \\
\text { coverage }\end{array}$ & 5,101 & $18,328,150$ & 451,873 & 3,886 & $16,265,760$ & 524,737 \\
\hline
\end{tabular}

${ }^{1}$ This is the cost of reaching the goal minus the cost of maintaining the current coverage levels of MMC and ART.

Tables 2 and 3 show the monetary benefit, cost, and the resulting benefit-to-cost ratio for each goal. While scaling up ART and MMC are both cost beneficial, the benefit-to-cost ratio for MMC is considerably higher. However, especially when using US\$5,000 per life year 
gained, scaling up ART is also a highly cost-beneficial intervention and, in our view, an important goal for HIV and AIDS for the period 2015 to 2030.

Table 2. Benefit, cost and benefit-to-cost ratio at US\$1,000 per life year gained

\begin{tabular}{|c|c|c|c|c|c|c|}
\hline \multirow{2}{*}{ Goal } & \multicolumn{3}{|c|}{$\mathbf{3 \%}$ Discount } & \multicolumn{2}{c|}{ 5\% Discount } \\
\cline { 2 - 6 } & $\begin{array}{c}\text { Benefit } \\
\text { (US\$1,000s) }\end{array}$ & $\begin{array}{c}\text { Cost } \\
\text { (US\$1,000s) }\end{array}$ & B:C ratio & $\begin{array}{c}\text { Benefit } \\
\text { (US\$1,000s) }\end{array}$ & $\begin{array}{c}\text { Cost } \\
\text { (US\$1,000s) }\end{array}$ & B:C ratio \\
\hline $\begin{array}{c}\text { Goal 1: } \\
\text { 90\% ART } \\
\text { coverage }\end{array}$ & $64,105,816$ & $19,311,250$ & 3.3 & $48,842,526$ & $16,452,647$ & 3.0 \\
\hline $\begin{array}{c}\text { Goal 2: } \\
90 \% \\
\begin{array}{c}\text { MMC } \\
\text { coverage }\end{array}\end{array}$ & $5,100,549$ & 451,873 & 11.3 & $3,886,133$ & 524,737 & 7.4 \\
\hline
\end{tabular}

Table 3. Benefit, cost and benefit-to-cost ratio at US\$5,000 per life year gained

\begin{tabular}{|c|c|c|c|c|c|c|}
\hline \multirow{2}{*}{ Goal } & \multicolumn{3}{|c|}{ 3\% Discount } & \multicolumn{3}{|c|}{$\mathbf{5 \%}$ Discount } \\
\cline { 2 - 7 } & $\begin{array}{c}\text { Benefit } \\
\text { (US\$1,000s) }\end{array}$ & $\begin{array}{c}\text { Cost } \\
\text { (US\$1,000s) }\end{array}$ & B:C ratio & $\begin{array}{c}\text { Benefit } \\
\text { (US\$1,000s) }\end{array}$ & $\begin{array}{c}\text { Cost } \\
\text { (US\$1,000s) }\end{array}$ & B:C ratio \\
\hline $\begin{array}{c}\text { Goal 1: } \\
\text { 90\% ART } \\
\text { coverage }\end{array}$ & $320,529,080$ & $19,311,250$ & 16.6 & $244,212,632$ & $16,452,647$ & 14.8 \\
\hline $\begin{array}{c}\text { Goal 2: } \\
90 \% \\
\begin{array}{c}\text { MMC } \\
\text { coverage }\end{array}\end{array}$ & $25,502,746$ & 451,873 & 56.4 & $19,430,663$ & 524,737 & 37.0 \\
\hline
\end{tabular}

\section{Limitations}

We decided to calculate the cost-benefit using life years gained rather than DALYs gained. This is a reasonable simplification in this model as MMC averts deaths through preventing new infections, meaning that the survivors are likely to be in full health. Similarly, with newer ART regimens, patients tend to suffer few if any side effects and, assuming good adherence to medication, no opportunistic infections. Thus, patients on ART are also mostly in good health. Another limitation of the model is that, for simplicity and demonstration 
reasons, we considered costs and benefits as if both ART and MMC were scaled up immediately in 2015 to $90 \%$ coverage; of course scaling up either intervention would take years.

In addition, the model does not account for the effect of MMC and ART on the beneficiaries' social and economic outcomes. HIV is strongly associated with poor socioeconomic outcomes, such as loss of employment (International Monetary Fund, 2004). In the case of MMC, therefore, the socioeconomic benefits are the socioeconomic losses that were averted by avoiding HIV infection. In the case of ART, socioeconomic benefits for patients will set in with a certain delay after the initiation of ART. While several studies have shown the existence of such socioeconomic benefits under ART (Bor et al., 2012; Rosen et al., 2014), they are difficult to quantify with sufficient precision to include in our model. Nonetheless, if these benefits were taken into account, the benefit-to-cost ratio would be even greater for both goals.

\section{Comparing the results with the "Rethink HIV" exercise}

In 2011, the Copenhagen Consensus Center, with funding from the Rush Foundation, commissioned a group of academics to analyze the costs and benefits of different approaches to tackling the HIV epidemic. The resulting book, entitled Rethink HIV, contains an assessment paper on approaches to preventing sexual transmission of HIV by Jere Behrman and Hans-Peter Kohler (Behrman and Kohler, 2011) and a paper on treatment of HIV/AIDS by Mead Over and Geoffrey Garnett (Over and Garnett, 2011). Although based on different models and assumptions, the findings in both these assessment papers are comparable to our results here. 
Over and Garnett modeled the cost-benefit comparison of spending an additional US\$10 billion on increasing ART coverage either among patients with a CD4 count $<204$ cells $/ \mu \mathrm{L}$ or $<411$ cells $/ \mu \mathrm{L}$ (Over and Garnett, 2011). Similar to our results, they found a benefit-to-cost ratio between 2.8 and 7.5 for ART depending on the scenario, value of life, and discount rate. In line with our argument that first increasing ART coverage among those with lower CD4 counts before expanding eligibility to higher CD4 count thresholds is more cost beneficial, Over and Garnett also find that spending an additional US\$10 billion on ART with a CD4count cut-off of 204 or 411 cells/ $\mu \mathrm{L}$ is more cost beneficial than spending an additional US\$30 billion on ART with a much higher CD4-count threshold of 800 cells/ $\mu \mathrm{L}$.

As one of three approaches to reduce sexual transmission of HIV, Behrman and Kohler modeled the costs and benefits of spending US\$10 billion on increasing MMC coverage among men in their 20s (Behrman and Kohler, 2011). Their high benefit-to-cost ratios of 22.9 to 82.9 for high-prevalence countries and 6.5 to 40.5 for medium-prevalence countries (depending on discount rate and value of life) are similar to our findings. Notably, the benefit-to-cost ratios are significantly higher than for the other two preventive approaches modeled by the authors, which are information campaigns through mass media and peer groups and HIV testing and counseling.

\section{Implementation challenges for increasing ART coverage}

Similar to any large-scale public health intervention, both increasing coverage of ART and MMC are likely to face several implementation challenges. The main implementation challenges for our first proposed goal, increasing ART coverage at $<350$ CD4 cells $/ \mu \mathrm{L}$, are to 1) identify HIV-infected people who are unaware of their status and 2) improve uptake of and retention in national ART programs. 
Increasing ART coverage hinges on the ability to identify HIV-infected individuals who are not yet aware of their positive status. The mainstay for HIV testing is voluntary counseling and testing offered at healthcare facilities. As an estimated 48\% of HIV-infected individuals globally do not know their status (UNAIDS, 2014a), this strategy has clearly fallen short of achieving universal testing coverage. New intensified testing efforts are therefore needed, which may have the added benefit of reducing HIV-related risk behavior (Fonner et al., 2012) and possibly even HIV incidence (Coates et al., 2014). Provider-initiated opt-out testing in various clinical settings has been shown to significantly increase testing uptake (Kennedy et al., 2013) and should, therefore, be rolled out further to a wider variety of clinical settings in HIV-hyperendemic countries. Facility-based testing alone, however, is unlikely to achieve universal testing coverage, and countries may therefore also need to implement extensive community-based testing programs, which have the potential to reach a large proportion of the population (Suthar et al., 2013). Such approaches could include door-to-door testing; mobile testing (e.g. at shopping centers); index testing (i.e. offering testing to the household members and/or sexual partners of people who tested positive); self-testing; and testing at workplaces, churches, and schools. The best strategy will likely depend on the local context, and further research should be conducted to identify innovative and cost-effective approaches to increase testing uptake.

The second main challenge to increasing ART coverage is to link those identified as HIVinfected to national ART programs and to ensure high levels of ART retention and adherence. A systematic review found that in sub-Saharan Africa only an average of $57 \%$ of patients who knew their positive HIV status completed assessment for ART eligibility. Of those eligible for ART, only 66\% started ART, and, of those who started ART, only 65\% were still 
on ART after three years (Kranzer et al., 2012). While these data are not from one cohort of patients, clearly a large proportion of patients are lost along the continuum of care. Similar to increasing testing rates, improving retention and adherence in HIV care is likely to require a combination of different approaches tailored to the local context. Evidence shows that mobile phone text message reminders and other types of reminders (e.g. diary cards), directly observed therapy, treatment supporters, food supplements, and education and counseling can significantly increase ART adherence (Bärnighausen et al., 2011; Finitsis, Pellowski, and Johnson, 2014). These promising approaches deserve consideration for routine implementation after further innovative modifications to improve their effectiveness and cost effectiveness in particular local contexts. For example, as distance to the clinic, transport costs, and time lost from the patient's usual activities to attend clinic appointments are important barriers to adherence (Mills et al., 2006) and because HIV patients who are stable on ART do not need to be seen by a health worker at each drug pickup visit, healthcare providers could encourage patients to join a geographical patient network by asking if 1) they would volunteer to pick up antiretroviral drugs for other patients from their community and/or 2) they would be willing to pick up ART from someone in their community. Once such geographical networks are established, text message reminders could not only remind patients of their drug refill appointment but also inform them when other patients in their network are traveling to the healthcare facility along with the individuals’ phone numbers. The healthcare facility could also implement a cost-sharing policy for transport and time lost from usual activities for these regional networks. As the use of smartphones, at least in urban areas, can be expected to starkly increase in developing countries over the next few years, such networks could in the future evolve into instant messaging groups and include applications that allow patients to identify the number, size, and location of such patient networks with the option to join a group online. 


\section{Implementation challenges for increasing MMC coverage}

The implementation challenges for increasing MMC coverage can be divided into supplyand demand-side obstacles. On the supply side, the main challenges are human resource constraints and monetary costs. HIV-hyperendemic countries face a serious human resources for health crisis. Thus, MMC campaigns that require a large chunk of clinicians' time will inevitably incur an opportunity cost of decreased availability and/or quality of care for other healthcare services. To minimize this opportunity cost, MMC programs should not only emphasize efficiency through simple measures, such as providing prebundled MMC kits to reduce preparation time and increasing the number of surgical bays in operating rooms, but also focus on task shifting from higher to lower healthcare cadres without compromising quality of care. MMC programs have typically used one doctor and one assistant to perform one of three types of surgical circumcision procedures (forceps guided, dorsal slit, or the sleeve resection method) (Tobian, Kacker, and Quinn, 2014), which allows for approximately 8-10 circumcisions daily (Curran et al., 2011). The WHO’s Models for Optimizing Volume and Efficiency (MOVE) strategy recommends training lower healthcare cadres, such as nurses and clinical officers, rather than physicians, in carrying out circumcisions in countries with a severe shortage of health workers (WHO, 2010b). In the MOVE strategy, assistants are responsible for preparing the circumcision (e.g. local anesthesia and assembling the kit), the "surgeon," who can be any health worker trained in performing MMC, then carries out the operation and inserts the primary sutures before the assistant completes the procedure by closing and dressing the wound. This approach can greatly increase efficiency; in South Africa and Zimbabwe, such a clinical team performed up to 50 circumcisions per day (Lissouba et al., 2010; WHO, 2010b). In addition, a systematic review has found that task shifting for MMC from doctors and specialists to nurses and clinical officers does not increase the rate of adverse events (Ford, Chu, and Mills, 2012). New technologies, such as 
the PrePex device or the Shang Ring, would obviate the need for a surgical procedure and could therefore further facilitate task shifting in MMC programs.

According to our model, the costs of scaling up MMC to achieve $90 \%$ coverage in hyperendemic countries will only be an additional US\$500 million, which is comparable to other model projections (Bollinger et al., 2014; Hankins, Forsythe, and Njeuhmeli, 2011; Njeuhmeli et al., 2011). Thus far, the United States President's Emergency Plan for AIDS Relief (PEPFAR) has funded around 80\% of circumcisions in the WHO priority countries for MMC scale up (Sgaier et al., 2014). Sgaier et al. name an insufficient level and lacking diversity of funding as key reasons for the failure of these priority countries to reach their target MMC coverage. Clearly, as international resources for HIV prevention decline, MMC scale up can only be successful if international donors and developing country governments prioritize funding for MMC.

While ethnic, cultural, and religious identities strongly influence the rates and timing of circumcision, the acceptability of MMC is high across sub-Saharan Africa, including in hyperendemic countries. A review of acceptability studies found that a median of $65 \%$ of uncircumcised men in sub-Saharan Africa were willing to become circumcised, $69 \%$ of women were in favor of circumcision for their partner, and $71 \%$ of men and $81 \%$ of women were willing to circumcise their son (Westercamp and Bailey, 2007). Despite this high level of acceptability, low demand for MMC, especially among older men, is seen as a key reason for the low rates of circumcision (Chinkhumba, Godlonton, and Thornton, 2014; Sgaier et al., 2014). Thus far, the main demand creation strategies for MMC programs have consisted of mass media campaigns, such as radio programs (Lissouba et al., 2010); community mobilization activities, including engagement with local community leaders in Kenya 
(Mwandi et al., 2011); poster campaigns and loudspeaker announcements in communities in Tanzania (Curran et al., 2011); the organization of block parties and door-to-door informational visits in South Africa (Lissouba et al., 2010); mobile MMC clinics that bring the service closer to the customer; and MMC campaigns at strategic times of the year, such as during school holidays (Lissouba et al., 2010; Mahler et al., 2011). To the best of our knowledge, only two studies have thus far examined the effect of financial incentives on demand for MMC. A randomized trial in Malawi found a moderate increase in demand among those who received a subsidy for the price of the MMC procedure (Chinkhumba, Godlonton, and Thornton, 2014). Similarly, a randomized trial in Kenya found a moderately higher demand for MMC, which is free of charge in Kenya, in those who were offered food vouchers in return for MMC (Thirumurthy et al., 2014). Although they would add to the cost of MMC programs, financial incentives are a particularly promising strategy for increasing demand for MMC. First, as the incentive can simply be provided at the MMC clinic after the procedure, administering the incentive and determining who has fulfilled the criteria to receive it is easy. Second, as opposed to financial incentive schemes to improve ART adherence, the incentive is only provided once, which reduces administrative burden and costs. Although the ethics of material incentives to increase demand for HIV prevention services can be debated (World Bank and USAID, 2011), our view is that a financial incentive is ethically defensible for improving MMC uptake because 1) MMC has significant positive externalities at the society level and 2) undergoing the procedure is costly for clients due to transport costs and time lost from work during recovery. In fact, clients in the Kenya trial have commented that the voucher value (US\$8.75 or US\$15.00) only partially offset their costs (Thirumurthy et al., 2014). 


\section{Vague versus specific goals}

The Sustainable Development Solutions Network, the UN General Assembly's Open Working Group on Sustainable Development Goals, and the High-Level Panel of Eminent Persons on the Post-2015 Development Agenda have each proposed a set of development goals for the period 2015-2030 (High-Level Panel of Eminent Persons on the Post-2015 Development Agenda, 2014; Open Working Group of the General Assembly on Sustainable Development Goals, 2014; Sustainable Development Solutions Network, 2014). All three proposals contain one broad goal on health (e.g. "to achieve health and wellbeing at all ages"; Sustainable Development Solutions Network, 2014) with several indicators or targets; for each proposal, one of these indicators or targets mentions HIV, such as "end the epidemic of AIDS” (Open Working Group of the General Assembly on Sustainable Development Goals, 2014) and "reduce the burden of disease from HIV/AIDS" (High-Level Panel of Eminent Persons on the Post-2015 Development Agenda, 2014). A goal that encompasses a country’s health sector in its entirety could be a substantial improvement to the current MDGs on health, which have been criticized as being too narrow in focusing only on certain diseases (Lomazzi, Borisch, and Laaser, 2014). In our view, however, the current proposed HIV targets are too vague to be useful to developing country governments and international organizations as they do not provide guidance on how progress should be measured or what interventions should be implemented. We have thus proposed goals that specify how the HIV epidemic should be targeted. While more instructive to both implementers and policy makers, this approach has the disadvantage that more cost-beneficial measures to address HIV may arise in the future through new technologies (e.g. an HIV vaccine) or new scientific evidence on existing technologies. If politically feasible, an ideal solution, therefore, would be the use of specific targets and indicators with an opportunity for regular (e.g. five-yearly) revision in light of new scientific evidence. 


\section{Conclusion}

In summary, scaling up MMC is a highly cost-beneficial intervention to address the HIV epidemic in hyperendemic countries for the period 2015-2030. In addition, our economic evaluation has demonstrated that increasing coverage of ART among the patients who need it most (i.e. those with a CD4 count $<350$ cells/ $\mu \mathrm{L}$ ) is also cost beneficial, albeit significantly less cost beneficial than MMC. Further, focusing ART first on those with a CD4 count $<350$ cells $/ \mu \mathrm{L}$ before gradually increasing the pool of ART-eligible patients to higher CD4 count thresholds is more cost effective than immediate expansion of ART eligibility to healthier HIV-infected patients. This approach also minimizes the danger of "crowding-out" effects whereby healthier patients accessing ART prevent sicker patients from receiving the lifesaving treatment. However, both of our goals, as is the case with any large-scale public health program, face significant implementation challenges. To successfully increase ART coverage, we recommend extensive facility- and community-based HIV testing programs and the scale up of innovative measures to improve retention across the entire HIV care cascade. To increase coverage of MMC, international donors and developing country governments should increase funding for both MMC programs and demand creation. Simultaneously, national MMC programs should focus on service efficiency through streamlining clinical procedures and task shifting to lower healthcare cadres without significantly compromising on quality of care. 


\section{References}

Aghokeng, A. F., Monleau, M., Eymard-Duvernay, S., Dagnra, A., Kania, D., Ngo-GiangHuong, N., ... Ayouba, A. (2014). Extraordinary heterogeneity of virological outcomes in patients receiving highly antiretroviral therapy and monitored with the World Health Organization public health approach in sub-saharan Africa and southeast Asia. Clinical Infectious Diseases : An Official Publication of the Infectious Diseases Society of America, 58(1), 99-109. doi:10.1093/cid/cit627

Auvert, B., Taljaard, D., Lagarde, E., Sobngwi-Tambekou, J., Sitta, R., \& Puren, A. (2005). Randomized, controlled intervention trial of male circumcision for reduction of HIV infection risk: the ANRS 1265 Trial. PLoS Medicine, 2(11), e298. doi:10.1371/journal.pmed.0020298

Bacchetti, P., \& Moss, A. R. (1989). Incubation period of AIDS in San Francisco. Nature, 338(6212), 251-3. doi:10.1038/338251a0

Baernighausen, T., Bloom, D. E., \& Humair, S. (2014). Human resources for treating HIV/AIDS: are the preventive effects of antiretroviral treatment a game changer? Under Review at Proceedings of the National Academy of Sciences.

Baernighausen, T., Humair, S., \& Bloom, D. (2012). Is HIV treatment-as-prevention a "game-changer"? An economic evaluation of HIV combination prevention. In International HIV Treatment as Prevention (TasP) Workshop. Vancouver.

Bailey, N. T. (1997). A revised assessment of the HIV/AIDS incubation period, assuming a very short early period of high infectivity and using only San Francisco public health data on prevalence and incidence. Statistics in Medicine, 16(21), 2447-58. Retrieved from http://www.ncbi.nlm.nih.gov/pubmed/9364653

Bailey, R. C., Moses, S., Parker, C. B., Agot, K., Maclean, I., Krieger, J. N., ... NdinyaAchola, J. O. (2007). Male circumcision for HIV prevention in young men in Kisumu, Kenya: a randomised controlled trial. Lancet, 369(9562), 643-56. doi:10.1016/S01406736(07)60312-2

Bärnighausen, T., Bloom, D. E., \& Humair, S. (2012). Economics of antiretroviral treatment vs. circumcision for HIV prevention. Proceedings of the National Academy of Sciences of the United States of America, 109(52), 21271-6. doi:10.1073/pnas.1209017110

Bärnighausen, T., Chaiyachati, K., Chimbindi, N., Peoples, A., Haberer, J., \& Newell, M.-L. (2011). Interventions to increase antiretroviral adherence in sub-Saharan Africa: a systematic review of evaluation studies. The Lancet. Infectious Diseases, 11(12), 94251. doi:10.1016/S1473-3099(11)70181-5

Behrman, J. R., \& Kohler, H.-P. (2011). Assessment Paper: Sexual Transmission of HIV. In B. Lomborg (Ed.), Rethink HIV (1st ed.). New York: Cambridge University Press. Retrieved from http://www.copenhagenconsensus.com/sites/default/files/behrman_kohler.pdf 
Bollinger, L., Adesina, A., Forsythe, S., Godbole, R., Reuben, E., \& Njeuhmeli, E. (2014). Cost drivers for voluntary medical male circumcision using primary source data from sub-Saharan Africa. PloS One, 9(5), e84701. doi:10.1371/journal.pone.0084701

Bor, J., Herbst, A. J., Newell, M.-L., \& Bärnighausen, T. (2013). Increases in adult life expectancy in rural South Africa: valuing the scale-up of HIV treatment. Science (New York, N.Y.), 339(6122), 961-5. doi:10.1126/science.1230413

Bor, J., Tanser, F., Newell, M.-L., \& Bärnighausen, T. (2012). In a study of a population cohort in South Africa, HIV patients on antiretrovirals had nearly full recovery of employment. Health Affairs (Project Hope), 31(7), 1459-69.

doi:10.1377/hlthaff.2012.0407

Chinkhumba, J., Godlonton, S., \& Thornton, R. (2014). The Demand for Medical Male Circumcision. American Economic Journal: Applied Economics, 6(2), 152-177. doi:10.1257/app.6.2.152

Coates, T. J., Kulich, M., Celentano, D. D., Zelaya, C. E., Chariyalertsak, S., Chingono, A., ... Eshleman, S. H. (2014). Effect of community-based voluntary counselling and testing on HIV incidence and social and behavioural outcomes (NIMH Project Accept; HPTN 043): a cluster-randomised trial. The Lancet. Global Health, 2(5), e267-77. doi:10.1016/S2214-109X(14)70032-4

Cohen, M. S., Chen, Y. Q., McCauley, M., Gamble, T., Hosseinipour, M. C., Kumarasamy, N., ... Fleming, T. R. (2011). Prevention of HIV-1 infection with early antiretroviral therapy. The New England Journal of Medicine, 365(6), 493-505. doi:10.1056/NEJMoa1105243

Curran, K., Njeuhmeli, E., Mirelman, A., Dickson, K., Adamu, T., Cherutich, P., ... Stanton, D. (2011). Voluntary medical male circumcision: strategies for meeting the human resource needs of scale-up in southern and eastern Africa. PLoS Medicine, 8(11), e1001129. doi:10.1371/journal.pmed.1001129

Dieleman, J. L., Graves, C. M., Templin, T., Johnson, E., Baral, R., Leach-Kemon, K., ... Murray, C. J. L. (2014). Global health development assistance remained steady in 2013 but did not align with recipients' disease burden. Health Affairs (Project Hope), 33(5), 878-86. doi:10.1377/hlthaff.2013.1432

Eaton, J. W., Johnson, L. F., Salomon, J. A., Bärnighausen, T., Bendavid, E., Bershteyn, A., ... Hallett, T. B. (2012). HIV treatment as prevention: systematic comparison of mathematical models of the potential impact of antiretroviral therapy on HIV incidence in South Africa. PLoS Medicine, 9(7), e1001245. doi:10.1371/journal.pmed.1001245

Essex, M., DeGruttola, V., Lebelonyane, R., \& Habibi, S. El. (2013). Botswana Combination Prevention Project. Retrieved February 20, 2015, from https://clinicaltrials.gov/ct2/show/NCT01965470

Finitsis, D. J., Pellowski, J. A., \& Johnson, B. T. (2014). Text message intervention designs to promote adherence to antiretroviral therapy (ART): a meta-analysis of randomized controlled trials. PloS One, 9(2), e88166. doi:10.1371/journal.pone.0088166 
Fonner, V. A., Denison, J., Kennedy, C. E., O’Reilly, K., \& Sweat, M. (2012). Voluntary counseling and testing (VCT) for changing HIV-related risk behavior in developing countries. The Cochrane Database of Systematic Reviews, 9, CD001224. doi:10.1002/14651858.CD001224.pub4

Ford, N., Chu, K., \& Mills, E. J. (2012). Safety of task-shifting for male medical circumcision: a systematic review and meta-analysis. AIDS (London, England), 26(5), 559-66. doi:10.1097/QAD.0b013e32834f3264

Gray, R. H., Kigozi, G., Serwadda, D., Makumbi, F., Watya, S., Nalugoda, F., ... Wawer, M. J. (2007). Male circumcision for HIV prevention in men in Rakai, Uganda: a randomised trial. Lancet, 369(9562), 657-66. doi:10.1016/S0140-6736(07)60313-4

Hankins, C., Forsythe, S., \& Njeuhmeli, E. (2011). Voluntary medical male circumcision: an introduction to the cost, impact, and challenges of accelerated scaling up. PLoS Medicine, 8(11), e1001127. doi:10.1371/journal.pmed.1001127

Havlir, D., \& Kamya, M. (2013). Sustainable East Africa Research in Community Health. Retrieved February 20, 2015, from https:/clinicaltrials.gov/show/NCT01864603

Hayes, R., Ayles, H., Beyers, N., Sabapathy, K., Floyd, S., Shanaube, K., ... Fidler, S. (2014). HPTN 071 (PopART): rationale and design of a cluster-randomised trial of the population impact of an HIV combination prevention intervention including universal testing and treatment - a study protocol for a cluster randomised trial. Trials, 15, 57. doi:10.1186/1745-6215-15-57

High-Level Panel of Eminent Persons on the Post-2015 Development Agenda. (2014). A new global partnership: eradicate poverty and transform economies through sustainable development. New York City. Retrieved from http://www.post2015hlp.org/wpcontent/uploads/2013/05/UN-Report.pdf

Hollingsworth, T. D., Anderson, R. M., \& Fraser, C. (2008). HIV-1 transmission, by stage of infection. The Journal of Infectious Diseases, 198(5), 687-93. doi:10.1086/590501

International Monetary Fund. (2004). The Macroeconomics of HIV/AIDS. (M. Haacker, Ed.) (Vol. 19, p. 344). Washington D.C.: International Monetary Fund.

Iwuji, C. C., Orne-Gliemann, J., Tanser, F., Boyer, S., Lessells, R. J., Lert, F., ... Dabis, F. (2013). Evaluation of the impact of immediate versus WHO recommendations-guided antiretroviral therapy initiation on HIV incidence: the ANRS 12249 TasP (Treatment as Prevention) trial in Hlabisa sub-district, KwaZulu-Natal, South Africa: study protocol for a clus. Trials, 14, 230. doi:10.1186/1745-6215-14-230

Kennedy, C. E., Fonner, V. A., Sweat, M. D., Okero, F. A., Baggaley, R., \& O’Reilly, K. R. (2013). Provider-initiated HIV testing and counseling in low- and middle-income countries: a systematic review. AIDS and Behavior, 17(5), 1571-90. doi:10.1007/s10461-012-0241-y

Kranzer, K., Govindasamy, D., Ford, N., Johnston, V., \& Lawn, S. D. (2012). Quantifying and addressing losses along the continuum of care for people living with HIV infection 
in sub-Saharan Africa: a systematic review. Journal of the International AIDS Society, 15(2), 17383. doi:10.7448/ias.15.2.17383

Lissouba, P., Taljaard, D., Rech, D., Doyle, S., Shabangu, D., Nhlapo, C., ... Auvert, B. (2010). A model for the roll-out of comprehensive adult male circumcision services in African low-income settings of high HIV incidence: the ANRS 12126 Bophelo Pele Project. PLoS Medicine, 7(7), e1000309. doi:10.1371/journal.pmed.1000309

Lomazzi, M., Borisch, B., \& Laaser, U. (2014). The Millennium Development Goals: experiences, achievements and what's next. Global Health Action, 7, 23695. Retrieved from http://www.pubmedcentral.nih.gov/articlerender.fcgi?artid=3926985\&tool=pmcentrez\& rendertype $=$ abstract

Mahler, H. R., Kileo, B., Curran, K., Plotkin, M., Adamu, T., Hellar, A., ... Fimbo, B. (2011). Voluntary medical male circumcision: matching demand and supply with quality and efficiency in a high-volume campaign in Iringa Region, Tanzania. PLoS Medicine, 8(11), e1001131. doi:10.1371/journal.pmed.1001131

Mills, E. J., Nachega, J. B., Bangsberg, D. R., Singh, S., Rachlis, B., Wu, P., ... Cooper, C. (2006). Adherence to HAART: a systematic review of developed and developing nation patient-reported barriers and facilitators. PLoS Medicine, 3(11), e438. doi:10.1371/journal.pmed.0030438

Mwandi, Z., Murphy, A., Reed, J., Chesang, K., Njeuhmeli, E., Agot, K., ... Bock, N. (2011). Voluntary medical male circumcision: translating research into the rapid expansion of services in Kenya, 2008-2011. PLoS Medicine, 8(11), e1001130. doi:10.1371/journal.pmed.1001130

Njeuhmeli, E., Forsythe, S., Reed, J., Opuni, M., Bollinger, L., Heard, N., ... Hankins, C. (2011). Voluntary medical male circumcision: modeling the impact and cost of expanding male circumcision for HIV prevention in eastern and southern Africa. PLoS Medicine, 8(11), e1001132. doi:10.1371/journal.pmed.1001132

Open Working Group of the General Assembly on Sustainable Development Goals. (2014). Open Working Group proposal for Sustainable Development Goals. New York City. Retrieved from http://sustainabledevelopment.un.org/content/documents/1579SDGs Proposal.pdf

Ortblad, K. F., Lozano, R., \& Murray, C. J. L. (2013). The burden of HIV: insights from the Global Burden of Disease Study 2010. AIDS (London, England), 27(13), 2003-17. doi:10.1097/QAD.0b013e328362ba67

Over, M., \& Garnett, G. (2011). Assessment Paper: Treatment. In B. Lomborg (Ed.), Rethink HIV (1st ed.). New York: Cambridge University Press. Retrieved from http://www.copenhagenconsensus.com/sites/default/files/over_garnett.pdf

Rosen, S., Larson, B., Rohr, J., Sanne, I., Mongwenyana, C., Brennan, A. T., \& Galárraga, O. (2014). Effect of antiretroviral therapy on patients' economic well being: five-year 
follow-up. AIDS (London, England), 28(3), 417-24.

doi:10.1097/QAD.0000000000000053

Sgaier, S. K., Reed, J. B., Thomas, A., \& Njeuhmeli, E. (2014). Achieving the HIV prevention impact of voluntary medical male circumcision: lessons and challenges for managing programs. PLoS Medicine, 11(5), e1001641. doi:10.1371/journal.pmed.1001641

Stop AIDS Now! (2014). MaxART - Implementation Study on Treatment as Prevention. Retrieved October 23, 2014, from http://www.stopaidsnow.org/maxart-implementationstudy-treatment-prevention

Sustainable Development Solutions Network. (2014). Proposed Sustainable Development Goals (SDGs) and Targets. New York City. Retrieved from http://unsdsn.org/wpcontent/uploads/2014/04/140417-Goals-and-Targets1.pdf

Suthar, A. B., Ford, N., Bachanas, P. J., Wong, V. J., Rajan, J. S., Saltzman, A. K., ... Baggaley, R. C. (2013). Towards universal voluntary HIV testing and counselling: a systematic review and meta-analysis of community-based approaches. PLoS Medicine, 10(8), e1001496. doi:10.1371/journal.pmed.1001496

Tanser, F., Bärnighausen, T., Grapsa, E., Zaidi, J., \& Newell, M.-L. (2013). High coverage of ART associated with decline in risk of HIV acquisition in rural KwaZulu-Natal, South Africa. Science (New York, N.Y.), 339(6122), 966-71. doi:10.1126/science.1228160

Thirumurthy, H., Masters, S. H., Rao, S., Bronson, M. A., Lanham, M., Omanga, E., ... Agot, K. (2014). Effect of providing conditional economic compensation on uptake of voluntary medical male circumcision in Kenya: a randomized clinical trial. JAMA, 312(7), 703-11. doi:10.1001/jama.2014.9087

Tobian, A. A. R., Kacker, S., \& Quinn, T. C. (2014). Male circumcision: a globally relevant but under-utilized method for the prevention of HIV and other sexually transmitted infections. Annual Review of Medicine, 65, 293-306. doi:10.1146/annurev-med-092412090539

UNAIDS. (2005). AIDS in Africa: Three scenarios to 2025. Geneva. Retrieved from http://data.unaids.org/publications/IRC-pub07/jc1058-aidsinafrica_en.pdf

UNAIDS. (2013a). Access to antiretroviral therapy in Africa: Status report on progress towards the 2015 targets. Geneva. Retrieved from http://www.unaids.org/sites/default/files/media_asset/20131219_AccessARTAfricaStatu sReportProgresstowards2015Targets_en_0.pdf

UNAIDS. (2013b). Global Report - UNAIDS report on the global AIDS epidemic 2013. Geneva. Retrieved from http://www.unaids.org/en/media/unaids/contentassets/documents/epidemiology/2013/gr 2013/UNAIDS_Global_Report_2013_en.pdf 
UNAIDS. (2014a). The Gap Report. Geneva. Retrieved from http://www.unaids.org/en/media/unaids/contentassets/documents/unaidspublication/201 4/UNAIDS_Gap_report_en.pdf

UNAIDS. (2014b). What are the different epidemiological scenarios?. Geneva. Retrieved from http://hivpreventiontoolkit.unaids.org/support_pages/faq_diff_epi_scenarios.aspx

UNICEF. (2014). Protection, care and support for children affected by HIV and AIDS. Retrieved October 01, 2014, from http://data.unicef.org/hiv-aids/care-support

United Nations. (2001). Declaration of Commitment on HIV/AIDS. New York City. Retrieved from http://www.unaids.org/en/media/unaids/contentassets/dataimport/publications/ircpub03/aidsdeclaration_en.pdf

United Nations. (2006). Political Declaration on HIV/AIDS. New York City. Retrieved from http://www.unaids.org/en/media/unaids/contentassets/dataimport/pub/report/2006/20060 615_hlm_politicaldeclaration_ares60262_en.pdf

United Nations. (2011). Political Declaration on HIV and AIDS: Intensifying Our Efforts to Eliminate HIV and AIDS. New York City. Retrieved from http://www.unaids.org/en/media/unaids/contentassets/documents/document/2011/06/201 10610_UN_A-RES-65-277_en.pdf

United Nations. (2014). United Nations Millennium Development Goals. United Nations. Retrieved September 30, 2014, from http://www.un.org/millenniumgoals/aids.shtml

Vasilakis, C. (2012). The social economic impact of AIDS: Accounting for intergenerational transmission, productivity and fertility. Economic Modelling, 29(2), 369-381. doi:10.1016/j.econmod.2011.11.006

Westercamp, N., \& Bailey, R. C. (2007). Acceptability of male circumcision for prevention of HIV/AIDS in sub-Saharan Africa: a review. AIDS and Behavior, 11(3), 341-55. doi:10.1007/s10461-006-9169-4

WHO. (2006). Antiretroviral therapy for HIV infection in adults and adolescents: recommendations for a public health approach. Geneva. Retrieved from http://www.who.int/hiv/pub/guidelines/artadultguidelines.pdf?ua=1

WHO. (2008). Task shifting: global recommendations and guidelines. Geneva: World Health Organization. Retrieved from http://www.who.int/workforcealliance/knowledge/resources/taskshifting_guidelines/en/

WHO. (2010a). Antiretroviral therapy for HIV infection in adults and adolescents: recommendations for a public health approach. Geneva. Retrieved from http://whqlibdoc.who.int/publications/2010/9789241599764_eng.pdf?ua=1

WHO. (2010b). Considerations for implementing models for optimizing the volume and efficiency of male circumcision services. Geneva. Retrieved from http://www.malecircumcision.org/programs/documents/mc_MOVE_2010_web.pdf 
WHO. (2013). Consolidated guidelines on the use of antiretroviral drugs for treating and preventing HIV infection. Geneva. Retrieved from http://apps.who.int/iris/bitstream/10665/85321/1/9789241505727_eng.pdf

WHO. (2014a). WHO Progress Brief - Voluntary medical male circumcision for HIV prevention in priority countries of East and Southern Africa. Geneva: World Health Organization. Retrieved from http://www.who.int/hiv/topics/malecircumcision/malecircumcision-info-2014/en/

WHO. (2014b). World Health Statistics 2014. Geneva. Retrieved from http://apps.who.int/iris/bitstream/10665/112738/1/9789240692671_eng.pdf?ua=1

Williams, B. G., Lloyd-Smith, J. O., Gouws, E., Hankins, C., Getz, W. M., Hargrove, J., ... Auvert, B. (2006). The potential impact of male circumcision on HIV in Sub-Saharan Africa. PLoS Medicine, 3(7), e262. doi:10.1371/journal.pmed.0030262

World Bank, \& USAID. (2011). The Ethics of Material Incentives for HIV Prevention. Washington D.C. Retrieved from http://siteresources.worldbank.org/INTHIVAIDS/Resources/3757981297872065987/WorldBankUSAIDDebate5Report.pdf 